\title{
Development of a Quinazoline-Based Chelating Ligand for Zinc Ion and Its Application to Validation of a Zinc-Ion-Coordinated Compound
}

\author{
Hiroshi Yamada, ${ }^{a}$ Akina Shirai, ${ }^{a}$ Keisuke Kato, ${ }^{b}$ Junko Kimura, ${ }^{a}$ Hideaki IchibA, ${ }^{a}$ \\ Takehiko YAJIMA, ${ }^{a}$ and Takeshi FuKUSHIMA ${ }^{*, a}$ \\ ${ }^{a}$ Department of Analytical Chemistry, Faculty of Pharmaceutical Sciences, Toho University; and ${ }^{b}$ Department of Organic \\ Chemistry, Faculty of Pharmaceutical Sciences, Toho University; 2-2-1 Miyama, Funabashi, Chiba 274-8510, Japan. \\ Received March 2, 2010; accepted March 18, 2010
}

A novel fluorescent chelating ligand, 2,4-[bis-(2-hydroxy-3-methoxybenzylidene)]-dihydrazinoquinazoline (HBQZ), was synthesized, and the fluorescence characteristics of its complex with metal ions were investigated. Among the 36 different metal ions tested in this study, it was found that HBQZ emits intense fluorescence at $506 \mathrm{~nm}$ with an excitation wavelength of $414 \mathrm{~nm}$ in the presence of $\mathrm{Zn}^{2+}$. The fluorescence intensity was almost constant in the $\mathrm{pH}$ range 3.5-10.5. Complexes of other metal ions with HBQZ did not show fluorescence, and the detection limit of $\mathrm{Zn}^{2+}$ was approximately $250 \mathrm{~nm}(16 \mathrm{ppb})$. The proposed method was applied to the validation test of a bioactive compound containing $\mathrm{Zn}^{2+}$ in its structure- an antibacterial and antifungal reagent, zinc pyrithione (ZnPT). In order to effectively release $\mathrm{Zn}^{2+}$ from $\mathrm{ZnPT}$, a pretreatment procedure involving heating with $\mathrm{H}_{3} \mathrm{PO}_{4}$ at $100{ }^{\circ} \mathrm{C}$ for 60 min was adopted. Under these conditions, a linear calibration curve was obtained in the $\mathrm{ZnPT}$ concentration range of $0.79-15.7 \mu_{\mathrm{M}}(0.25-5.0 \mathrm{ppm})$; the correlation coefficient and the relative standard deviation were 0.996 and within $3.1 \%(n=5)$, respectively.

Key words metal-ion complex; quinazoline; fluorescence; zinc ion; zinc pyrithione

Metal ions can act as a Lewis acid, and due to this property, they have been artificially incorporated into drugs, pigments, or dietary supplements ${ }^{1-5)}$ in order to gain the intrinsic activity. Metal-ion-coordinated compounds are generally validated using atomic absorption spectrometry (AAS), because metal ions can be selectively quantified by AAS. However, a functionalized ligand that can chelate a metal ion selectively to emit fluorescence can also be used for such validation.

Recently, we developed a fluorescent chelating ligand, 2,4[bis-(2,4-dihydroxybenzylidene)]-dihydrazinoquinazoline (DBHQ), which can selectively chelate with $\mathrm{Ga}^{3+}$ ions to emit fluorescence at $470 \mathrm{~nm}$ with an excitation wavelength of $405 \mathrm{~nm}$. ${ }^{6}$ The basic structure of DBHQ is a quinazoline skeleton with two Schiff base moieties that serve as chelating sites.

In DBHQ, two 2,4-dihydroxyphenyl groups are attached to the quinazoline moiety via Schiff bases, which are considered to play a role in chelation with $\mathrm{Ga}^{3+}$. This moiety may be suitable for identifying the ionized atomic structure of $\mathrm{Ga}^{3+}$. On the other hand, an $o$-vanillin moiety has recently been incorporated into fluorescent chelating ligands such as $N$-o-vanillidine-2-amino- $p$-cresol (OVAC) ${ }^{7}{ }^{7} o$-vanillin furfuralhydrazone $(\mathrm{OVFH}),{ }^{8)}$ and $o$-vanillin-8-aminoquinoline, ${ }^{9)}$ which can chelate $\mathrm{Al}^{3+}, \mathrm{Ga}^{3+}$, and $\mathrm{Cr}^{3+}$, respectively. The benzaldehyde moiety of $o$-vanillin can be used to produce a Schiff base via a coupling reaction with an amino group, and the lone pair of electrons on the oxygen atom of the phenolic hydroxyl group may act as a Lewis base for chelation with metal ions. Similarly, $o$-vanillin has been used as a building block for functionalized chelating ligands.

In this study, we designed and synthesized a previously developed quinazoline-based fluorescent ligand as a structural analog of DBHQ. In this analog, the 2,4-dihydroxybenzene in DBHQ is replaced with the $o$-vanillin moiety, and its ability as a fluorescent chelating ligand was investigated. Con- sequently, although 2,4-[bis-(2-hydroxy-3-methoxybenzylidene)]-dihydrazinoquinazoline (HBQZ, Fig. 1a) itself shows very weak fluorescence, it can selectively bind with $\mathrm{Zn}^{2+}$ to emit fluorescence at $506 \mathrm{~nm}$ with an excitation wavelength of $414 \mathrm{~nm}$. Further, we exploited the fluorometric properties of HBQZ to detect $\mathrm{Zn}^{2+}$ for the validation of a $\mathrm{Zn}^{2+}$-containing compound, because several compounds such as drugs or supplements contain $\mathrm{Zn}^{2+}$ in their chemical structure. In the present study, an antibacterial and antifungal reagent, zinc pyrithione $(\mathrm{ZnPT}){ }^{10-17)}$ in which a bidentate bis-( $N$-oxopyridine-2-thionato) ligand is coordinated with the zinc ion, was used as the $\mathrm{Zn}^{2+}$-containing compound.

\section{Experimental}

Chemicals Anthranilic acid and hydrazine monohydrate were purchased from Tokyo Kasei Co., Ltd. (Tokyo, Japan). Urea, dimethyl sulfoxide (DMSO), phosphoryl chloride $\left(\mathrm{POCl}_{3}\right), \mathrm{ZnPT}$, phosphoric acid, and quinine sulfate were purchased from Wako Pure Chemical Industries Co., Ltd. (Osaka, Japan). $o$-Vanillin was purchased from Kanto Kagaku Co., Ltd. (Tokyo, Japan). $\mathrm{H}_{2} \mathrm{O}$ was used after purification using an Autopure WR600G (Yamato Scientific Co., Ltd., Tokyo, Japan). The cations and anions tested in this study, which were purchased in the form of salts containing $\mathrm{NO}_{3}^{-}, \mathrm{SO}_{4}^{2-}$, and $\mathrm{Cl}^{-}$, were of atomic absorption grade and purchased from Wako Pure Chemical Industries.

Apparatus Excitation and fluorescence spectra were measured on a spectrofluorometer (FP-6300; Jasco Co., Tokyo, Japan) with slit widths of $10 \mathrm{~nm}$. All fluorescence and absorption data were collected in a temperaturecontrolled room $\left(25^{\circ} \mathrm{C}\right)$. IR spectra were recorded on an FT/IR-4100 (Jasco) instrument. Mass spectra were measured on a JMS-600H (JEOL, Ltd.,

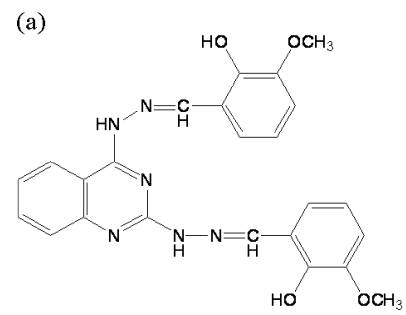

(b)

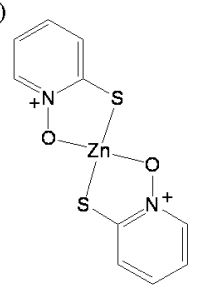

Fig. 1. Chemical Structures of (a) HBQZ and (b) Zinc Pyrithione (ZnPT) 
Tokyo, Japan). NMR spectra were measured by JEOL ECP1 (JEOL Ltd., Tokyo, Japan) (500 MHz for ${ }^{1} \mathrm{H}$ and ${ }^{13} \mathrm{C}$ ) with tetramethylsilane as the internal standard. The refractive indices of the solvents were measured using an Abbe refractometer (model ER-1, ERMA Inc., Tokyo, Japan).

Synthesis and Characterization of HBQZ 2,4-Dihydrazinoquinazoline (1) was synthesized according to the method described in our previous paper. $\left.{ }^{6}\right)$ Compound $1(13.0 \mathrm{mmol})$ was mixed with $o$-vanillin $(1.16 \mathrm{~g}$, $0.40 \mathrm{~mol})$ in EtOH $(350 \mathrm{ml})$, and the obtained solution was refluxed at $80^{\circ} \mathrm{C}$ for $3 \mathrm{~h}$. After the solution was heated to dryness, the obtained brownish residue was recrystallized using $\mathrm{MeOH}$ to give $\mathrm{HBQZ}$ in the form of a yellow powder. The product was recrystallized using $\mathrm{MeOH}$ to obtain the final purified product (yield: $45.0 \%$ ). FAB-MS: $m / z 459[\mathrm{M}+\mathrm{H}]^{+}$; Elemental Anal. Calcd for $\mathrm{C}_{24} \mathrm{H}_{22} \mathrm{O}_{4} \mathrm{~N}_{6}$ : C, $62.87 ; \mathrm{H}, 4.84 ; \mathrm{N}, 18.33 \%$. Found: $\mathrm{C}, 62.86$; $\mathrm{H}, 4.95 ; \mathrm{N}, 18.36 \%$. FT-IR (solid phase) $\left(\mathrm{cm}^{-1}\right): 3394,3304\left(v_{\mathrm{O}-\mathrm{H}}\right), 1602$ $\left(v_{\mathrm{C}=\mathrm{N}}\right), 1266,1250\left(v_{\mathrm{Ar}-\mathrm{O}}\right) .{ }^{1} \mathrm{H}-\mathrm{NMR}\left(\mathrm{CDCl}_{3}+\mathrm{CF}_{3} \mathrm{CO}_{2} \mathrm{H}\right) \delta(\mathrm{ppm}): 3.87$ $(3 \mathrm{H}, \mathrm{s}), 3.93(3 \mathrm{H}, \mathrm{s}), 6.88-7.04(6 \mathrm{H}, \mathrm{m}), 7.46(1 \mathrm{H}, \mathrm{dt}, J=2.0,8.0 \mathrm{~Hz})$, $7.75-7.80(2 \mathrm{H}, \mathrm{m}), 8.09(1 \mathrm{H}, \mathrm{d}, J=8.4 \mathrm{~Hz}), 8.43(1 \mathrm{H}, \mathrm{s}), 8.55(1 \mathrm{H}, \mathrm{s}) .{ }^{13} \mathrm{C}-$ NMR $\left(\mathrm{CDCl}_{3}+\mathrm{CF}_{3} \mathrm{CO}_{2} \mathrm{H}\right) \delta(\mathrm{ppm}): 56.0,56.3,109.5,115.0,115.3,116.7$, $117.0,118.0,121.4,121.6,122.2,123.6,123.9,127.4,137.0,138.0,145.2$, 146.5, 147.5, 147.7, 150.2, 152.0, 154.1, 156.7. Melting point: $283-284^{\circ} \mathrm{C}$.

Screening Assay of Metal Ions Coordinated with HBQZ The probability of 36 different metal ions being coordinated with HBQZ to induce fluorescence emission was investigated. Solutions containing $100 \mu \mathrm{l}$ of the metal ions (1000 ppm), $100 \mu \mathrm{l}$ of a $100 \mu \mathrm{m}$ solution of HBQZ in DMSO, and $100 \mu \mathrm{l}$ of a buffer solution at various $\mathrm{pH}$ values $(3.5-10.5)$ were taken in glass test tubes. Buffer solutions with $\mathrm{pH} 3.5-5.0,5.5-7.0$, and 7.5-10.5 were prepared from $100 \mathrm{~mm} \mathrm{CH}_{3} \mathrm{CO}_{2} \mathrm{Na}-\mathrm{CH}_{3} \mathrm{CO}_{2} \mathrm{H}, \mathrm{N}$-(2-hydroxyethyl)piperazine- $N^{\prime}-2$-ethanesulfonic acid (HEPES)- $\mathrm{NH}_{3}$, and $\mathrm{NH}_{4} \mathrm{Cl}-\mathrm{NH}_{3}$, respectively. Each test tube was irradiated by UV light from a $\mathrm{D}_{2}$ lamp in a dark room. The sample emitting intense fluorescence was concluded to be the solution containing the fluorescent HBQZ complex. In this experiment, the fluorescence emission was evaluated by visual assessment.

Sample Preparation In the case of measuring fluorescence of HBQZ$\mathrm{Zn}^{2+}$ complex, sample preparation was performed as follows. In a polypropyrene test tube, $1.0 \mathrm{ml}$ of $50 \mathrm{~mm}$ acetate buffer $(\mathrm{pH} 4.5)$ was added to the sample solution. This was followed by adding $200 \mu \mathrm{l}$ of a $60 \mu \mathrm{m}$ HBQZ in DMSO, and was left to stand for $10 \mathrm{~min}$ at room temperature. Then, the solution was diluted tenfold with distilled 2-propanol, and the spectrum of the diluted solution was measured in a $1.0 \times 1.0 \mathrm{~cm}$ quartz cell.

Excitation and Emission Spectra For the measurement of spectra, $500 \mu \mathrm{l}$ of a $30.8 \mu \mathrm{M}\left(2 \mathrm{ppm} \mathrm{Zn}^{2+}\right)$ solution of $\mathrm{Zn}\left(\mathrm{NO}_{3}\right)_{2}$ in $\mathrm{H}_{2} \mathrm{O}$ was treated as described above.

Effect of Interfering Ions on Fluorescence In experiments involving interfering ions, $400 \mu \mathrm{l}$ of an aqueous solution of $\mathrm{Zn}\left(\mathrm{NO}_{3}\right)_{2}(7.69 \mu \mathrm{M}$, i.e., $0.5 \mathrm{ppm} \mathrm{Zn}^{2+}$ ) and $100 \mu \mathrm{l}$ of an aqueous solution of each metal ion or anion $\left(31.0-15.0 \times 10^{3} \mu \mathrm{M}\right)$ were successively added to $1.0 \mathrm{ml}$ of $50 \mathrm{~mm}$ acetate buffer ( $\mathrm{pH} 4.5$ ), and treated in a similar manner in sample preparation. If a cation or anion was found to affect the fluorescence, the procedure was repeated for an ion concentration diluted twice with $\mathrm{H}_{2} \mathrm{O}$. This process was repeated until the ion concentration at which the fluorescence emission of the $\mathrm{HBQZ}-\mathrm{Zn}^{2+}$ complex did not change was obtained. An error within $\pm 5 \%$ in the measured fluorescence intensity was considered tolerable.

Binding Ratio of $\mathbf{Z n}^{2+}$ to $\mathbf{H B Q Z}$ Next, $500 \mu 1$ of $\mathrm{Zn}^{2+}$ solutions of different concentrations $(1.54-76.9 \mu \mathrm{M})$ were mixed with $200 \mu \mathrm{l}$ of $60 \mu \mathrm{M}$ HBQZ solution. This was followed by the addition of $1.0 \mathrm{ml}$ of $100 \mathrm{~mm}$ acetate buffer ( $\mathrm{pH} 4.5)$. The fluorescence intensity of each solution was measured at $506 \mathrm{~nm}$ with an excitation wavelength of $414 \mathrm{~nm}$. Further, $500 \mu l$ of a $15.4 \mu \mathrm{M}(1.0 \mathrm{ppm}) \mathrm{Zn}^{2+}$ solution was mixed with $200 \mu \mathrm{l}$ of HBQZ solutions $(5.0-150 \mu \mathrm{M})$, and treated in a similar manner. The binding ratio was determined using the following molar ratio method. The fluorescence intensities were plotted against the molar ratio of $\mathrm{Zn}^{2+}$ with $\mathrm{HBQZ}$, and the molar ratio of HBQZ coordinated with $\mathrm{Zn}^{2+}$ was determined stoichiometrically from the plots.

The apparent binding constant of HBQZ with $\mathrm{Zn}^{2+}$ was calculated using the modified Benesi-Hildebrand Eq. 1 as reported by Roy et al. ${ }^{18)}$

$$
\Delta F=\Delta F_{\max }+(1 / K[C])\left(\Delta F_{\max }\right)
$$

where $\Delta F$ and $\Delta F_{\max }$ are equal to $F-F_{0}$ and $F_{\max }-F_{0}$, respectively. $F_{0}, F$, and $F_{\max }$ are the fluorescence intensities of HBQZ, HBQZ with test $\mathrm{Zn}^{2+}$ concentrations $(7.69,12.3,15.4,30.8 \mu \mathrm{M})$, and HBQZ with the maximum $\mathrm{Zn}^{2+}$ concentration $(76.9 \mu \mathrm{M})$, respectively. $K$ and $[C]$ are the apparent binding constant and the test concentration of $\mathrm{Zn}^{2+}$, respectively. $\Delta F_{\max }-\Delta F$ was plotted against $1 /[C]$, and the value of $K$ was obtained from the slope of the line.
Electrospray Ionization (ESI) Mass Spectrometry Next, $200 \mu \mathrm{l}$ of $1.0 \mathrm{~mm} \mathrm{Zn}^{2+}$ solutions were mixed with $200 \mu \mathrm{l}$ of $1.0 \mathrm{~mm} \mathrm{HBQZ}$ solution.

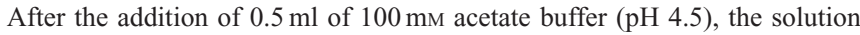
mixture was diluted with $50 \% \mathrm{MeOH}$ in $\mathrm{H}_{2} \mathrm{O}$ containing $1 \%$ acetic acid to $10 \mathrm{ml}$. The samples were injected at a constant flow rate of $5 \mu \mathrm{l} / \mathrm{min}$ using a syringe pump. All mass spectrometry (MS) data were acquired using an LCQ ion trap mass spectrometer (ThermoFisher Scientific, Yokohama, Japan) equipped with an electrospray ionization source, and the mass spectrometer was operated in the positive-ion mode. The experimental conditions were as follows: spray needle voltage, $5 \mathrm{kV}$; heated capillary temperature, $200^{\circ} \mathrm{C}$; and sheath gas flow rate, 40 (arbitrary units). Mass spectra were measured in the full ion scan mode for a mass-to-charge $(\mathrm{m} / \mathrm{z})$ ratio in the range of 200-2000.

Fluorescence Quantum Yield and Calibration Curve According to a previous method, ${ }^{19)}$ the fluorescence quantum yield $(\phi)$ of HBQZ in the presence or absence of $\mathrm{Zn}^{2+}$ was determined using quinine sulfate as a reference compound. In addition, the $\phi$ value of HBQZ $-\mathrm{Zn}^{2+}$ in the presence of $10 \mathrm{mM} \mathrm{H}_{3} \mathrm{PO}_{4}$ was also determined.

In brief, $1.0 \mathrm{ml}$ of acetate buffer ( $\mathrm{pH} 4.5$ ) was added to $500 \mu 1$ of $2.0 \mathrm{ppm}$ $\mathrm{Zn}^{2+}$ and/or $500 \mu \mathrm{l}$ of $20 \mathrm{~mm} \mathrm{H}_{3} \mathrm{PO}_{4}$. Finally, $200 \mu \mathrm{l}$ of $60 \mu \mathrm{M} \mathrm{HBQZ}$ was added and treated as described above. In this case, a fluorescence integral with an excitation wavelength of $414 \mathrm{~nm}$ was obtained, and the absorbance at $414 \mathrm{~nm}$ was measured by using a Jasco V-650 spectrophotometer (Jasco, Tokyo, Japan). A calibration curve was drawn by plotting the values of $F-F_{0}$ against $\mathrm{Zn}^{2+}$ concentration (ppb). Then, $500 \mu$ l of a $\mathrm{Zn}^{2+}$ solution $(50-1000 \mathrm{ppb})$ was used for the calibration curve $(n=5)$. Detection limit (DL) was determined by the obtained calibration curve using the following Eq. 2.

$$
\mathrm{DL}=3.3 \sigma / s
$$

where $\sigma$ and $s$ are the standard deviation of $0 \mathrm{ppm} \mathrm{Zn}^{2+}$ and slope of the calibration curve, respectively $(n=5)$.

Release of $\mathbf{Z n}^{2+}$ from $\mathbf{Z n P T} \mathrm{ZnPT}$ was dissolved in $10 \mathrm{~mm} \mathrm{HCl}$, $\mathrm{HNO}_{3}, \mathrm{H}_{3} \mathrm{PO}_{4}$, and $\mathrm{H}_{2} \mathrm{SO}_{4}(5.0 \mathrm{ppm} \mathrm{ZnPT})$, and was heated at $100{ }^{\circ} \mathrm{C}$ for $60 \mathrm{~min}$. After the solution was cooled, $500 \mu \mathrm{l}$ of the solution was sampled and was treated in a similar manner $(n=5)$. $\mathrm{ZnPT}$ dissolved in $20 \mathrm{~mm} \mathrm{H}_{3} \mathrm{PO}_{4}$ $(5.0 \mathrm{ppm})$ was heated at $40,60,80$, and $100{ }^{\circ} \mathrm{C}$ until $120 \mathrm{~min}$, respectively. Then, $500 \mu \mathrm{l}$ of the solution at each time point was treated $(n=5)$. Next, $500 \mu$ of $0.787-15.7 \mu \mathrm{M} \mathrm{ZnPT}$ in $20 \mathrm{~mm} \mathrm{H}_{3} \mathrm{PO}_{4}$ were heated at $100^{\circ} \mathrm{C}$ for $60 \mathrm{~min}$ and then used for obtaining the calibration curve for $\mathrm{ZnPT}(n=5)$.

\section{Results and Discussion}

Synthesis and Properties of HBQZ HBQZ was successfully synthesized in accordance with the procedure outlined in our previous paper, $\left.{ }^{6}\right)$ judging from the data of the elemental analysis, FAB-MS, ${ }^{1} \mathrm{H}-\mathrm{NMR},{ }^{13} \mathrm{C}-\mathrm{NMR}$, and FT-IR. Next, from among the 36 kinds of metal ions, the metal ion that could coordinate with HBQZ to afford a fluorescent complex was identified using different $\mathrm{pH}$-buffered solutions. Consequently, in the presence of $\mathrm{Zn}^{2+}$, intense fluorescence was observed upon irradiation from the $\mathrm{D}_{2}$ lamp. Thus, $\mathrm{Zn}^{2+}$-chelating and fluorescent property of $\mathrm{HBQZ}$ was mainly studied in this study.

Fluorescence Spectrum and Calibration Curve for $\mathbf{Z n}^{2+}$ Figure 2 shows the excitation and emission spectra of HBQZ with $\mathrm{Zn}^{2+}$ in $50 \mathrm{~mm}$ acetate buffer (pH 4.5). The optimum excitation and emission wavelengths were 414 and $506 \mathrm{~nm}$, respectively. As shown in Fig. 2, the intensity of fluorescence emitted by the HBQZ- $\mathrm{Zn}^{2+}$ complex was approximately ten times that exhibited by HBQZ alone in the presence of $2 \mathrm{ppm} \mathrm{Zn}^{2+}$. The fluorescence intensity was almost constant in the $\mathrm{pH}$ range 3.5-10.5 (data not shown), indicating that the HBQZ- $\mathrm{Zn}^{2+}$ complex is formed over a broad $\mathrm{pH}$ range, although most fluorescent ligands can chelate metal ions in neutral to alkaline solutions. Among the organic solvents used for the dilution of the HBQZ- $\mathrm{Zn}^{2+}$ complex and measurements of the fluorescence intensity, the most intense fluorescence was observed in 2-propanol, and therefore, 2- 
propanol was used in further studies. A linear calibration curve was obtained in the $\mathrm{Zn}^{2+}\left(r^{2}=0.994\right)$ concentration range $0.77-15.4 \mu \mathrm{M}(50-1000 \mathrm{ppb})$, and the precision (relative standard deviation (RSD)) at $12.3 \mu \mathrm{M} \mathrm{Zn^{2+ }}$ was within $3.60 \%(n=5)$. The detection limit of $\mathrm{Zn}^{2+}$ was approximately $250 \mathrm{~nm}(16 \mathrm{ppb})$.

Effect of Additive Ions on Fluorescence As shown in Table 1, the coexistence of most metal cation or anion with $\mathrm{Zn}^{2+}$ did not affect the fluorescence emission of the HBQZ$\mathrm{Zn}^{2+}$ complex. However, the addition of more than $2.0 \mathrm{eq}$ of $\mathrm{Co}^{2+}, \mathrm{Cu}^{2+}, \mathrm{Fe}^{3+}$, and $\mathrm{Mn}^{2+}$ to $\mathrm{Zn}^{2+}$ resulted in fluorescence quenching. It is suggested that these metal ions could also be chelated by HBQZ, but the complex may not emit fluorescence.

Binding Ratio of $\mathrm{HBQZ}$ to $\mathrm{Zn}^{2+}$ and Fluorescence Quantum Yield Figures $3 \mathrm{a}$ and $\mathrm{b}$ show the fluorescence intensity plotted against the molar ratio of $\mathrm{Zn}^{2+}$ to $\mathrm{HBQZ}$

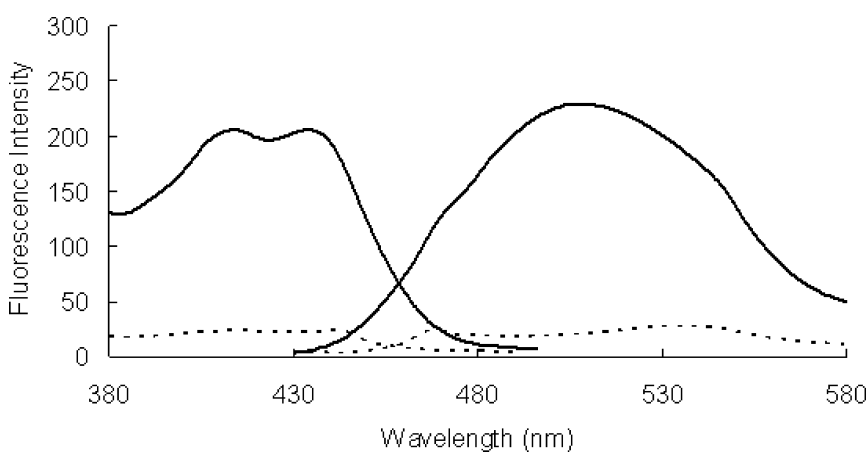

Fig. 2. Excitation and Emission Spectra of HBQZ in the Presence (Solid Line) or Absence (Dotted Line) of $\mathrm{Zn}^{2+}$

Table 1. Effect of Interfering Ions on the Detection of $7.69 \mu \mathrm{M}(0.5 \mathrm{ppm})$ $\mathrm{Zn}^{2+}$ Using $60 \mu \mathrm{M} \mathrm{HBQZ} \mathrm{(Tolerable} \mathrm{Error:} \pm 5 \%$ )

$$
\begin{aligned}
\text { Tolerance ratio } & (\mathrm{m} / \mathrm{m}) \\
>500 & \mathrm{~K}^{+}, \mathrm{CH}_{3} \mathrm{CO}_{2}^{-}, \mathrm{NO}_{3}^{-}, \mathrm{SO}_{4}^{2-}, \mathrm{Cl}^{-}, \mathrm{Br}^{-}, \mathrm{I}^{-}, \mathrm{PO}_{4}^{3-}, \mathrm{Na}^{+} \\
250 & \mathrm{Ag}^{+}, \mathrm{Ge}^{4+} \\
100 & \mathrm{Mg}^{2+} \\
50 & \mathrm{Be}^{2+}, \mathrm{Ba}^{2+}, \mathrm{Sr}^{2+}, \mathrm{Ca}^{2+}, \mathrm{Pb}^{2+}, \mathrm{Cd}^{2+} \\
25 & \mathrm{Hg}^{2+}, \mathrm{ZrO}^{2+} \\
10 & \mathrm{Ti}^{4+} \\
5 & \mathrm{Sn}^{2+}, \mathrm{Al}^{3+}, \mathrm{Ni}^{2+}, \mathrm{In}^{3+}, \mathrm{Cr}_{2} \mathrm{O}_{7}^{2-} \\
2 & \mathrm{Co}^{2+}, \mathrm{Cu}^{2+}, \mathrm{Fe}^{3+}, \mathrm{Mn}^{2+}
\end{aligned}
$$

Tolerance ratio $(\mathrm{m} / \mathrm{m})$ was expressed as a ratio of the tested ion $(\mathrm{mol})$ to $\mathrm{Zn}^{2+}$ ion (mol).

(a)

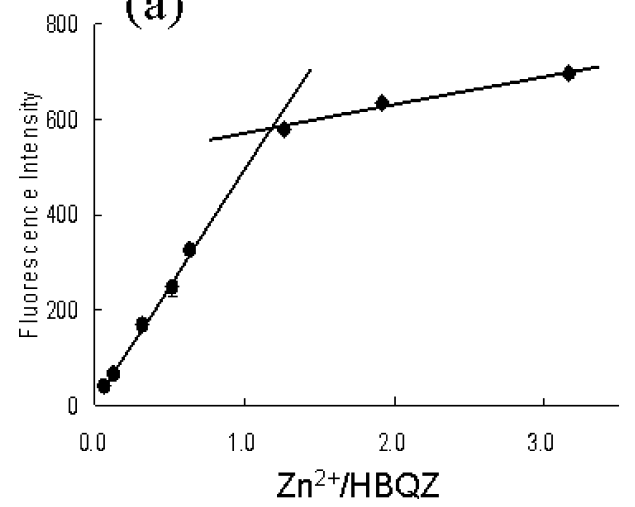

and that of $\mathrm{HBQZ}$ to $\mathrm{Zn}^{2+}$, respectively. Both plots indicate that $\mathrm{HBQZ}$ binds to $\mathrm{Zn}^{2+}$ in a $1: 1$ molar ratio. In addition, the ESI-MS spectrum of the solution of the HBQZ- $\mathrm{Zn}^{2+}$ complex showed the presence of ions with $m / z$ of 520.1 (data not shown); these are molecular ions of the HBQZ- $\mathrm{Zn}^{2+}$ complex $\left[(\mathrm{HBQZ}-2 \mathrm{H}+\mathrm{Zn})^{+}\right]$. This result confirms that the binding ratio of the $\mathrm{HBQZ}-\mathrm{Zn}^{2+}$ complex was $1: 1$. The binding association constant $K$ was determined by using the Benesi-Hildebrand method, and $\log K$ was approximately 5.6. The $\phi$ value of the HBQZ $-\mathrm{Zn}^{2+}$ complex was 0.349 , while that of HBQZ alone was 0.021 . These $\log K$ and $\phi$ values were considered to be sufficient for the fluorescence detection of $\mathrm{Zn}^{2+}$.

Fluorescence Detection of $\mathrm{Zn}^{2+}$ from $\mathrm{ZnPT}$ Next, HBQZ was applied to the validation of a bioactive compound containing coordinated $\mathrm{Zn}^{2+}$ in its structure. Many $\mathrm{Zn}^{2+}$-coordinated compounds are used as drugs, nutrients, or supplements. For example, $N$-(3-aminopropionyl)-L-histidinato zinc (Z-103) shows anti-ulcer activity, ${ }^{1)}$ while bis(pyrrole-2-carboxylato)zinc shows insulinomimetic activity. ${ }^{2)}$ Such $\mathrm{Zn}^{2+}$ containing drugs are usually validated using AAS, because AAS can achieve selective quantification of a metal ion. In AAS measurement, however, a hollow cathode lamp is required for each metal ion; the flame from the lamp is supplemented with combustible acetylene gas for atomization of the sample. Fluorescence detection using a functionalized ligand, which can selectively chelate the metal ion, is preferred over AAS measurement due to its inherent simplicity and safety. Therefore, in order to exploit the usefulness of the validation test of a $\mathrm{Zn}^{2+}$-coordinated compound, in the present study, we attempted to validate an antibacterial and antifungal reagent $\mathrm{ZnPT}$, which has $\mathrm{Zn}^{2+}$ ions coordinated bilaterally with electrons on the sulfur and oxygen atoms of 1-hydroxypyridine-2-thione (pyrithione) (Fig. 1b). ${ }^{10,11)}$

In our preliminary experiments, in which HBQZ was directly reacted with $\mathrm{ZnPT}$ in $50 \mathrm{~mm}$ acetate buffer at $\mathrm{pH} 4.0$, the observed fluorescence intensity of the $15-63 \mu \mathrm{M} \mathrm{ZnPT}$ solution was considerably low-one-tenth of that of the solution containing $15-63 \mu \mathrm{M}$ free $\mathrm{Zn}^{2+}$. This result suggests that insufficient $\mathrm{Zn}^{2+}$ ions were released from $\mathrm{ZnPT}$ when the acetate buffer with $\mathrm{pH} 4.0$ was used. Therefore, it was necessary to release free $\mathrm{Zn}^{2+}$ from the chelated $\mathrm{Zn}^{2+}$ in $\mathrm{ZnPT}$. On the basis of the fact that $\mathrm{p} K_{\mathrm{a}}$ of pyrithione is 4.6 , $\mathrm{Zn}^{2+}$ could be completely released from $\mathrm{ZnPT}$ in the region with acidic $\mathrm{pH}$. Thus, $\mathrm{HCl}, \mathrm{HNO}_{3}, \mathrm{H}_{3} \mathrm{PO}_{4}$, and $\mathrm{H}_{2} \mathrm{SO}_{4}$ were

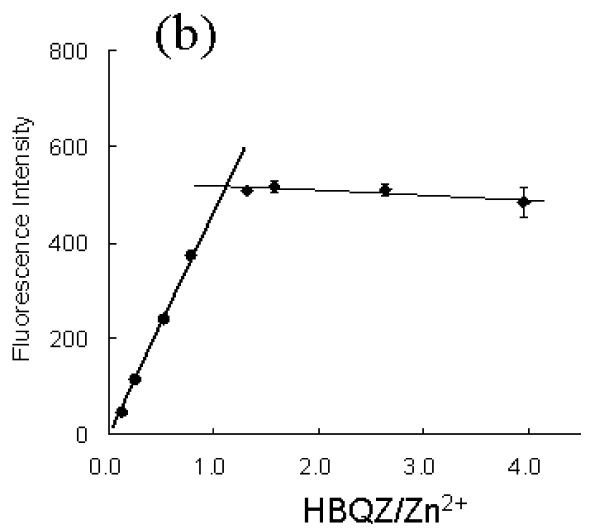

Fig. 3. Fluorescence Intensity of $\mathrm{HBQZ}-\mathrm{Zn}^{2+}$ Complex (a) at a Binding Ratio of $\mathrm{Zn}^{2+}$ to $\mathrm{HBQZ}$ and (b) at a Binding Ratio of $\mathrm{HBQZ}$ to $\mathrm{Zn}{ }^{2+}$ 

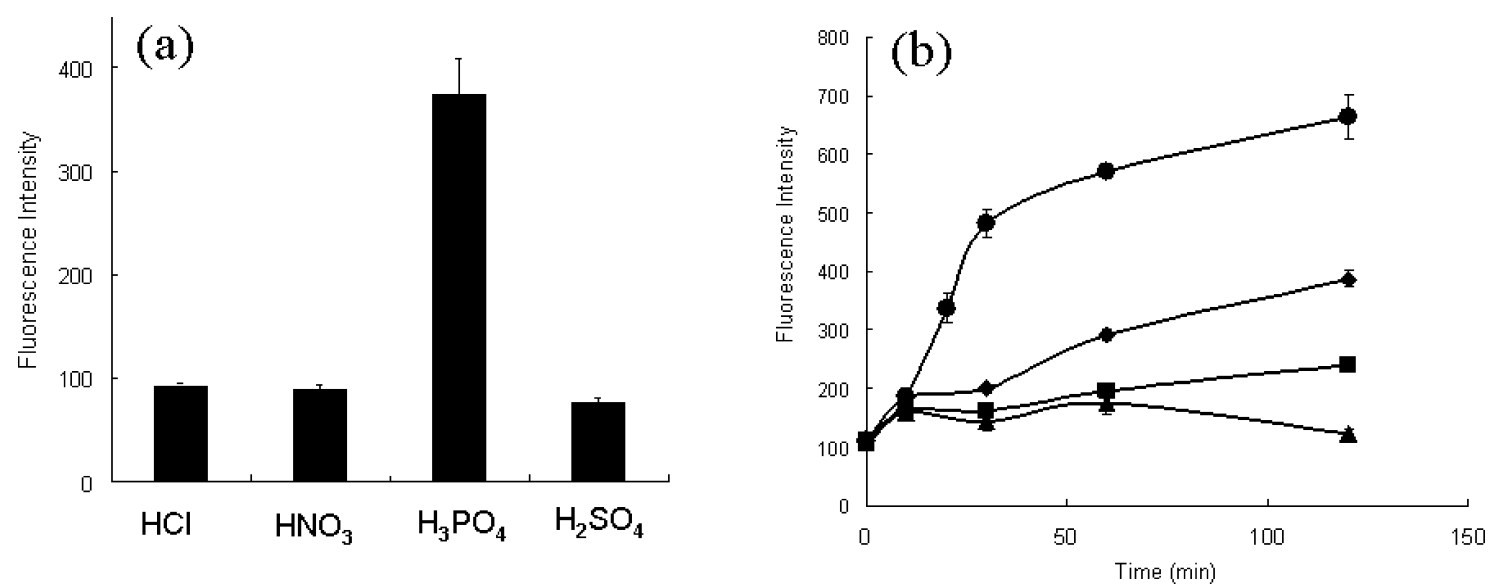

Fig. 4. (a) Effect of $10 \mathrm{~mm}$ Inorganic Acids on Fluorescence Intensity of HBQZ- $\mathrm{Zn}^{2+}$ Complex Produced from $\mathrm{ZnPT}$ (Mean $+\mathrm{S} . \mathrm{D}$., $n=5$ ); (b) Time Course of Change in Fluorescence Intensity of $\mathrm{HBQZ}-\mathrm{Zn}^{2+}$ Complex Produced from $\mathrm{ZnPT}$, Plotted as a Function of Heating Time in $20 \mathrm{~mm} \mathrm{H}_{3} \mathrm{PO}_{4}$ (Mean \pm S.D., $n=5$ )

Closed circle: $100^{\circ} \mathrm{C}$, diamond: $80^{\circ} \mathrm{C}$, square: $60^{\circ} \mathrm{C}$, and triangle: $40^{\circ} \mathrm{C}$.

tested for identifying the type of inorganic acid required for the release of $\mathrm{Zn}^{2+}$ from $\mathrm{ZnPT}$. The highest fluorescence intensity of the HBQZ- $\mathrm{Zn}^{2+}$ complex was observed in the presence of $\mathrm{H}_{3} \mathrm{PO}_{4}$ (Fig. 4a). Therefore, $\mathrm{H}_{3} \mathrm{PO}_{4}$ was utilized for the release of free $\mathrm{Zn}^{2+}$ from $\mathrm{ZnPT}$. It is still not clear why $\mathrm{H}_{3} \mathrm{PO}_{4}$ was effective for the detection of free $\mathrm{Zn}^{2+}$ in $\mathrm{ZnPT}$. The cooperative coordination between the phosphoryl group in $\mathrm{H}_{3} \mathrm{PO}_{4}$ and $\mathrm{Zn}^{2+}$ was thought to have enhanced the fluorescence intensity of the HBQZ- $\mathrm{Zn}^{2+}$ complex. Certainly, the $\phi$ value of the HBQZ- $\mathrm{Zn}^{2+}$ complex in the presence of $10 \mathrm{~mm} \mathrm{H}_{3} \mathrm{PO}_{4}$ was 0.712 , whereas the $\phi$ value of the HBQZ $-\mathrm{Zn}^{2+}$ complex alone was 0.349 . Similar phenomena were observed in our previous study, in which a quinazolinetype ligand, 2,4-[bis-(2,4-dihydroxybenzylidene)]-dihydrazinoquinazoline (DBHQ), ${ }^{6,20)}$ was used. It was recently reported that the structural analog, DBHQ, with $\mathrm{Ga}^{3+}$ was also enhanced by the addition of phosphoryl compounds or dihydrophosphate ions. ${ }^{20)}$

Figure $4 \mathrm{~b}$ shows the time course of the change in the fluorescence intensity as a function of heating time. As shown in Fig. 4 b, heating at $100{ }^{\circ} \mathrm{C}$ resulted in high fluorescence intensity after the onset of the reaction, indicating that the release of free $\mathrm{Zn}^{2+}$ from $\mathrm{ZnPT}$ was accelerated at $100^{\circ} \mathrm{C}$. Therefore, in this study, heating was carried out at $100^{\circ} \mathrm{C}$ for $60 \mathrm{~min}$. Under these conditions, a linear calibration curve was obtained for the ZnPT concentration range 0.79-15.7 $\mu \mathrm{M}(0.25-5.0 \mathrm{ppm})$; the correlation coefficient $\left(r^{2}\right)$ and RSD were 0.996 and within $3.1 \%(n=5)$, respectively. These data indicate that the fluorescence method involving the use of HBQZ is suitable for the validation of $\mathrm{ZnPT}$. The detection sensitivity of $\mathrm{Zn}^{2+}$ by using HBQZ was not superior to that by using AAS; however, fluorescence detection of $\mathrm{Zn}^{2+}$ has the advantage of simplicity. Therefore, HBQZ can be used for the validation of a compound containing $\mathrm{Zn}^{2+}$, owing to its capacity to capture $\mathrm{Zn}^{2+}$ ions.

\section{Conclusion}

A novel quinazoline-based chelating ligand, $\mathrm{HBQZ}$, with an $o$-vanillin moiety was newly developed. It was shown that HBQZ fluoresced selectively with $\mathrm{Zn}^{2+}$ and that HBQZ can be used for the validation of $\mathrm{ZnPT}$ after a pretreatment procedure. The proposed fluorescent method using HBQZ will be useful for the validation test for a bioactive $\mathrm{Zn}^{2+}$-containing compound.

Acknowledgment The authors thank Ms. Ziyu Song, Toho University, for her help with manuscript preparation.

References

1) Nishide M., Yoshikawa Y., Yoshikawa E. U., Matsumoto K., Sakurai H., Kajiwara N. M., Chem. Pharm. Bull., 56, 1181-1183 (2008).

2) Ito M., Tanaka T., Suzuki Y., Jpn. J. Pharmacol., 52, 513—521 (1990).

3) Ferruzzi M. G., Failla M. L., Schwartz S. J., J. Agric. Food Chem., 50, 2173-2179 (2002)

4) Chen J. H., Jiang S. J., J. Agric. Food Chem., 56, 1210-1215 (2008).

5) Nève J., Hanocq M., Peretz A., Khalil F. A., Pelen F., Biol. Trace Elem. Res., 32, 201-212 (1992).

6) Kimura J., Yamada H., Ogura H., Yajima T., Fukushima T., Anal. Chim. Acta, 635, 207-213 (2009).

7) Kara D., Fisher A., Hill S. J., J. Environ. Monit., 9, 994-1000 (2007).

8) Tang B., Chen Z. Z., Zhang N., Zhang J., Wang Y., Talanta, 68, 575580 (2006).

9) Tang B., Yue T. X., Wu J. S., Dong Y. M., Ding Y., Wang H. J., Talanta, 64, 955-960 (2004).

10) Doose C.A., Ranke J., Stock F., Bottin-Weber U., Jastorff B., Green Chem., 6, 259-266 (2004).

11) Bao V. W. W., Leung K. M. Y., Kwok K. W. H., Zhang A. Q., Lui G. C. S., Mar. Pollut. Bull., 57, 616-623 (2008).

12) Kondoh Y., Takano S., J. Chromatogr., 408, 255-262 (1987).

13) Shih Y., Zen J. M., Kumar A. S., Chen P. Y., Talanta, 62, 912-917 (2004).

14) Thomas K. V., J. Chromatogr. A, 833, 105-109 (1999).

15) Doose C. A., Szaleniec M., Behrend P., Muller A., Jastorff B., J. Chromatogr. A, 1052, 103-110 (2004).

16) Yamaguchi Y., Kumakura A., Sugasawa S., Harino H., Yamada Y., Shibata K., Senda T., Int. J. Environ. Anal. Chem., 86, 83-89 (2006).

17) Bones J., Thomas K. V., Paull B., J. Chromatogr. A, 1132, 157-164 (2006).

18) Roy P., Dhara K., Manassero M., Ratha J., Banerjee P., Inorg. Chem., 46, 6405-6412 (2007).

19) Bag B., Bharadwaj P. K., J. Lumin., 126, 27-36 (2007).

20) Kimura J., Yamada H., Yajima T., Fukushima T., J. Lumin., 129, $1362-1365$ (2009). 